\title{
Perspectives of Patients with Insulin-Treated Type 1 and Type 2 Diabetes on Hypoglycemia: Results of the HAT Observational Study in Central and Eastern European Countries
}

\author{
Martin Haluzik (DD - Adam Kretowski - Krzysztof Strojek • Leszek Czupryniak • \\ Andrej Janez • Peter Kempler · Michal Andel · Tsvetalina Tankova • \\ Mihail Boyanov · Lea Smircic Duvnjak · Laszlo Madacsy • \\ Iwona Tarnowska $\cdot$ Marcin Zychma $\cdot$ Nebojsa Lalic \\ Received: November 10, 2017 / Published online: March 9, 2018 \\ (C) The Author(s) 2018. This article is an open access publication
}

\section{ABSTRACT}

Introduction: The aim of this study was to determine the level of awareness of hypoglycemia, the level of fear for hypoglycemia, and the response to hypoglycemic events among insulin-treated diabetes patients from Central and Eastern Europe (CEE). The impact of hypoglycemia on the use of healthcare resources and patient productivity was also assessed.

Enhanced content To view enhanced content for this article go to https://doi.org/10.6084/m9.figshare. 5909137.

\section{Haluzik ( $\square)$}

Diabetes Centre and Centre for Experimental

Medicine, Institute for Clinical and Experimental

Medicine, Vídeňská 1958/9, 14021 Prague 4, Czech Republic

e-mail: halm@ikem.cz; mhalu@lf1.cuni.cz

\section{A. Kretowski}

Department of Endocrinology, Diabetology and Internal Diseases, Medical University of Białystok, Białystok, Poland

\section{K. Strojek}

Department of Internal Diseases Diabetology and Cardiometabolic Diseases, School of Medicine with the Division of Dentistry (SMDZ) in Zabrze, Medical University of Silesia, Katowice, Poland

L. Czupryniak

Department of Diabetology and Internal Medicine, Medical University of Warsaw, Warsaw, Poland
Methods: This was a multicenter, non-interventional, two-part, patient self-reported questionnaire study that comprised both a retrospective cross-sectional evaluation and a prospective observational evaluation. Study participants were insulin-treated adult patients with type 1 diabetes mellitus (T1DM) or type 2 diabetes mellitus (T2DM) from CEE.

Results: Most patients (85.4\% T1DM and 83.6\% T2DM) reported normal hypoglycemia awareness. The median hypoglycemia fear score was 5 out of 10 for T1DM and 4 out of 10 for T2DM patients. Patients increased glucose monitoring, consulted a doctor/nurse, and/or
A. Janez
Department of Endocrinology, Diabetes and
Metabolic Diseases, University Medical Center,
Ljubljana, Slovenia
P. Kempler
First Department of Medicine, Faculty of Medicine, Semmelweis University, Budapest, Hungary

\section{Andel}
Center for Research of Nutrition, Metabolism and Diabetes, Third Faculty of Medicine, Charles University, Prague, Czech Republic
T. Tankova
Clinical Center of Endocrinology, Medical University-Sofia, Sofia, Bulgaria

\author{
M. Boyanov \\ Clinic of Endocrinology and Metabolism, \\ Department of Internal Medicine, University \\ Hospital Alexandrovska, Medical University-Sofia,
} Sofia, Bulgaria 
reduced the insulin dose in response to hypoglycemia. As a consequence of hypoglycemia, patients took leave from work/studies or arrived late and/or left early. Hospitalization was required for $31(1.2 \%)$ patients with T1DM and $66(2.1 \%)$ patients with T2DM.

Conclusion: Hypoglycemia impacts patients' personal and social functioning, reduces productivity, and results in additional costs, both direct (related to increased use of healthcare resources) and indirect (related to absenteeism.

Funding: Novo Nordisk.

Keywords: Diabetes; Healthcare costs; Hypoglycemia; Hypoglycemia fear; Insulin therapy

\section{INTRODUCTION}

One of the most substantial risks related to the treatment of diabetes mellitus (DM) is hypoglycemia, which negatively affects patient's health and overall quality of life (QoL) [1]. The results of the ACCORD clinical trial showed that intensive glucose-lowering therapy (with a target level of glycated hemoglobin [HbA1c] of $<$ $6.0 \%$ ) was associated with more frequent hypoglycemic events requiring medical or nonmedical assistance and with higher mortality than less intensive treatment regimens [2].

Among the many negative long-term consequences of hypoglycemia, the higher risk of micro- and macrovascular events with potential

L. Smircic Duvnjak

Vuk Vrhovac University Clinic for Diabetes-UH

Merkur, School of Medicine, University of Zagreb,

Zagreb, Croatia

L. Madacsy

First Department of Pediatrics, Faculty of Medicine, Semmelweis University Budapest, Budapest,

Hungary

I. Tarnowska $\cdot$ M. Zychma

Novo Nordisk Pharma, Warsaw, Poland

N. Lalic

Clinic for Endocrinology Diabetes and Metabolic Diseases, Clinical Center of Serbia (CCS), Faculty of Medicine, University of Belgrade, Belgrade, Serbia fatal outcome is an important clinical concern as such events may occur months or years after episodes of severe hypoglycemia [3]. For example, hypoglycemia has been shown to cause cardiovascular (CV) events by increasing inflammation, endothelial dysfunction, and abnormal sympathoadrenal responses and by activating blood coagulation [4]. Novel drugs associated with lower risk of hypoglycemia (either in monotherapy or as an addition to standard antidiabetic therapy) can, however, reduce the $\mathrm{CV}$ risk in T2DM patients $[5,6]$. Hypoglycemia can also affect cognitive function. For example, a history of severe hypoglycemic events has been associated with dementia [7]. Recurrent hypoglycemia has also been shown to cause chronic mood disorders, including depression and anxiety [8]. In addition, hypoglycemia has been shown to impair personal and social functioning and reduce QoL in patients with type 1 diabetes (T1DM) and type 2 diabetes (T2DM), resulting in problems related to employment, the ability to drive a motor vehicle, physical activity, and the fear of being dependent on other family members or caregivers. Indeed, this fear of dependency on caregivers and loss of self-control has been shown to influence the interpersonal relationships of patients affected by hypoglycemia [9].

The American Diabetes Association (ADA) clinical recommendations, published in 2017, underline the essential role of patients in preventing and managing hypoglycemia [1]. A patient-centered approach not only includes close direct communication, but also patientreported outcomes, structured and individual patient education, individualized treatment, and self-monitoring and self-management of the DM [10]. Indeed, patients' understanding of the disease and its complications is a key factor to the successful management of any chronic disease, and DM with its risk of hypoglycemia is no exception.

Nonetheless, the striking results of an analysis based on online questionnaires revealed that $65 \%$ of patients with T1DM and $50-59 \%$ of patients with T2DM rarely or never informed their general practitioner/specialist of hypoglycemic events, while 16 and 26\%, respectively, had not been asked about hypoglycemia 
during routine visits [11]. Some patients did not discuss hypoglycemia with their physicians thinking that it is a "private issue" or a "personal failure"; others did not understand the importance of hypoglycemia [12].

Recently published findings of the HAT study, a large global patient-reported study on hypoglycemia, indicated high rates of hypoglycemia, with large variations between geographical regions [13]. These observed regional differences in hypoglycemia incidence raised the question as to whether they had resulted from true ethnic and population variations, from differences in treatment modalities [14], or from differences in the ways patients perceive and manage their disease.

Therefore, the aim of this study was to analyze in detail the HAT data reported by T1DM and T2DM patients from Central and Eastern Europe (CEE) according the patient's perspective, which was not presented in the paper by Khunti et al. [13]. We focused on patients' perception of hypoglycemia, the impact of hypoglycemia on patients' personal and societal functioning, and utilization of healthcare resources.

\section{METHODS}

\section{Study Design and Subjects}

This was a multicenter, non-interventional, two-part study based on a patient self-assessment questionnaire (SAQ) comprising both a 6-month and a 4-week retrospective cross-sectional evaluation (Part 1) and a 4-week prospective observational evaluation (Part 2). The study was conducted between 5 September 2012 and 30 December 2013 at 262 sites in CEE. Consecutive eligible patients were enrolled in the study during a routinely scheduled clinical consultation with their healthcare provider. Participants of this study came from Bulgaria, Croatia, Czech Republic, Hungary, Poland, Romania, Serbia and Montenegro, Slovakia, and Slovenia.

Each country was to identify $80-150$ investigators (doctors working in either primary or secondary care). Each investigator was to recruit and enroll five to ten consecutive patients who met the inclusion criteria, namely, adults with T1DM or T2DM treated with insulin for at least 12 months. Illiterate patients or patients otherwise unable to complete a written survey were excluded from the study. Patients who were hospitalized at the time of study start were also excluded.

\section{Assessments}

Part 1 of the questionnaire was used to record baseline demographic and clinical information. A history of hypoglycemic events was established, with data on severe events collected for 6 months and 4 weeks, respectively, prior to baseline and data on non-severe events collected for only 4 weeks prior to baseline. Information on each patient's knowledge, awareness, and fear of hypoglycemia was also collected. Part 1 of the questionnaire was completed during routine clinical consultations with healthcare providers.

Part 2 of the questionnaire was completed 4 weeks after baseline and evaluated the occurrence of both severe and non-severe hypoglycemic events over the 4 weeks following entry into the baseline study. To assist recall and maintain anonymity, patients were provided with a diary to record hypoglycemic events. If a patient recorded more hypoglycemic events using the patient diary than recorded in Part 2 of the SAQ, then the data in the patient diary were used to calculate the prevalence of hypoglycemia in the 4 weeks after baseline as a mean to compensate for potential underestimations attributable to recall bias. Part 2 of the questionnaire and the patient diary were returned by post.

Parts 1 and 2 of the questionnaire were both used to evaluate patients' responses to hypoglycemic events and the effect of these events on healthcare utilization and productivity during the time frame of the study.

In accordance to the ADA definition, hypoglycemia was defined as an acute complication of $\mathrm{DM}$ with $\mathrm{a} \leq 3.9 \mathrm{mmol} / \mathrm{L}(70 \mathrm{mg} / \mathrm{dl})$ fall in blood glucose level that exposes a patient to potential harm [15, 16]. Non-severe 
hypoglycemia was defined as an event managed by the patient alone; severe hypoglycemia was defined (based on the ADA definition) as any hypoglycemic event requiring assistance of another person to administer carbohydrate, glucagon, or other resuscitative actions [16]. Nocturnal hypoglycemia was defined by protocol as any hypoglycemic event occurring between midnight and 0600 hours.

The awareness of hypoglycemia was categorized based on answers given to the question 'Do you have symptoms when you have a low sugar level?', where 'always' and 'usually' denoted normal, 'occasionally' denoted impaired, and 'never' denoted severely impaired awareness.

Fear of hypoglycemia was assessed by the patients themselves on 0 to 10 semi-quantitative scale, where ' 0 ' denoted not afraid at all, and ' 10 ' denoted absolutely terrified.

\section{Compliance with Ethics Guidelines}

This study was conducted in accordance with the Declaration of Helsinki (2004) and the International Conference on Harmonization (ICH) Guidelines for Good Clinical Practice (1996). The study design was approved by the country-specific regulatory authorities and ethical committees. All participants of the study provided signed informed consent.

\section{Statistical Analysis}

Baseline refers to data collected using the Part 1 SAQ, while follow-up refers to data collected using the Part 2 SAQ and, where applicable, the patient diary. Continuous data were summarized in terms of the number of observations, mean, standard deviation, upper quartile, median, lower quartile, minimum, maximum, and missing number of observations, unless otherwise stated. Categorical data were summarized in terms of the number of patients providing data at the relevant time point $(n)$, frequency counts, and percentages. Incidence rates of hypoglycemia together with the 95\% confidence intervals were calculated as the number of events per patient year. Statistical analysis was performed using SAS ${ }^{\circledR}$ version 9.2 or later (SAS Institute, Cary, NC, USA).

\section{RESULTS}

\section{Baseline Characteristics}

In total, 10,414 patients were invited to participate in the study. Overall, 9504 patients completed Part 1 of the SAQ (3135 with T1DM and 6369 with T2DM); 9229 patients (3040 with T1DM and 6189 with T2DM) completed Part 2 of the SAQ, and 7647 patients (2826 with T1DM and 4821 with T2DM) completed patient diaries.

\section{Demographic and Clinical Characteristics}

Disposition of the patients by country was as follows: $537(5.6 \%)$ were from Bulgaria, 315 (3.3\%) were from Croatia, 1472 (15.5\%) were from the Czech Republic, 1667 (17.5\%) were from Hungary, 2448 (25.8\%) were from Poland, 1190 (12.5\%) were from Romania, 1064 (11.2\%) were from Serbia and Montenegro, 500 were from Slovakia $(5.3 \%)$, and 311 were $(3.3 \%)$ from Slovenia. Patients with T1DM were younger than those with T2DM and had a longer mean duration of insulin use. Mean HbA1c level was similar in both groups of patients. The last measured $\mathrm{HbA} 1 \mathrm{c}$ value in $>50 \%$ of all patients was in the range of $53-75 \mathrm{mmol} / \mathrm{mol}$ (7.0-9.0\%). Most patients were treated with short-acting and long-acting insulins, and about $25 \%$ of all patients took oral anti-diabetes drugs. Most patients in the overall population experienced hypoglycemic events. Table 1 provides detailed information on patient baseline characteristics.

\section{Knowledge about hypoglycemia}

At baseline, most of the patients were familiar with the definition of hypoglycemia, and most had experienced a hypoglycemic episode. More than $40 \%$ of patients recognized hypoglycemia on the basis of symptoms and low blood glucose concentration. 
Table 1 Demographic and clinical characteristics at baseline (study entry)

Demographic and clinical characteristics

Age (years)

Mean (SD)

Sex $[n(\%)]$

Male

Female

Employment status $[n(\%)]$

Student

Full-time employment

Part-time employment

Unemployed

Pensioned

Other

Duration of diabetes (years)

$n$

Mean (SD)

Duration of insulin treatment (years)

$n$

Mean (SD)

Self-reported last $\mathrm{HbAlc}(\mathrm{mmol} / \mathrm{mol})$ levels

$n$

Mean (SD)

Self-reported last HbAlc (\%) levels ${ }^{\mathrm{a}}$

Mean (SD)

Patients with self-reported last HbAlc (\%) levels [ $n$ (\%)]

$n$

$<7.0 \%$,

$\geq 7.0 \%$ and $\leq 9.0 \%$

$>9.0 \%$

Treatment of diabetes $[n(\%)]$

Short-acting insulin

2879

$61.0(15.68)^{\mathrm{b}}$

$7.7(3.6)$

2879

$905(31.4)$

$1513(52.6)$

$461(16.0)$

$2718(86.9)$

$2525(80.7)$

$166(5.3)$

$416(13.3)$ $62.5(9.30)^{\mathrm{b}}$

$3095(48.7)^{\mathrm{b}}$

$3265(51.3)$

$3(<0.1)$

1140 (18.1)

327 (5.2)

$296(4.7)$

4427 (70.3)

$107(1.7)$

6331

$13.6(7.87)^{\mathrm{b}}$

6351

$7.1(5.78)^{\mathrm{b}}$

5438

$60.9(15.02)^{\mathrm{b}}$

$7.7(3.5)$

5438

1549 (28.5)

3147 (57.9)

$742(13.6)$

$3451(54.6)$

3895 (61.6)

2381 (37.6)

$53(0.8)$ 
Table 1 continued

\begin{tabular}{lll}
\hline Demographic and clinical characteristics & T1DM patients $(\boldsymbol{N}=\mathbf{3 1 3 5})$ & T2DM patients $(\boldsymbol{N}=\mathbf{6 3 6 9})$ \\
\hline Oral anti-diabetes treatments & $84(2.7)$ & $2124(33.6)$ \\
Injectable anti-diabetes treatments (excluding insulin) & $3(<0.1)$ & $51(0.8)$ \\
Use of continuous glucose monitoring device $[n(\%)]$ & & $715(11.5)$ \\
Yes & $536(17.4)$ & $5338(85.9)$ \\
No & $2486(80.9)$ & $160(2.6)$ \\
Not sure & $52(1.7)$ & $6303(99.1)$ \\
Self-measurement of blood glucose levels $[n(\%)]$ & & $58(0.9)$ \\
Yes & $3119(99.6)$ & $829(13.1)$ \\
No & $12(0.4)$ & $143(2.3)$ \\
Self-reported hypoglycemia $[n(\%)]$ & & $5357(84.6)$ \\
Yes & $3069(98.3)$ & $4(1.4)$ \\
No & $8(0.3)$ & \\
Not sure & & \\
\hline
\end{tabular}

HbAlc Glycated hemoglobin; SD standard deviation, T1DM type 1 diabetes, T2DM type 2 diabetes

a Calculated

b Reported previously by Khunti et al. [13]

In total, a minority of patients who used blood glucose measurement to determine if they had hypoglycemia provided values inconsistent with the standard definition of a hypoglycemic event. These details are given in Table 2.

\section{Incidence, Awareness and Fear of Hypoglycemia}

\section{Incidence of Hypoglycemia}

During the 4 weeks preceding baseline, most of patients reported at least one hypoglycemic event. During the 4 weeks after baseline, the percentages of patients who reported hypoglycemic events were similar to those in the 4 weeks prior to baseline (Table 3 ).

The incidence of patient-reported nocturnal hypoglycemic events was much higher in the T1DM patient population than in the T2DM patient population (Table 3 ).

\section{Awareness of Hypoglycemia}

Hypoglycemia awareness at baseline was similar in T1DM and T2DM patients. Most patients reported normal awareness $(85.4 \%$ of T1DM and $83.6 \%$ of $\mathrm{T} 2 \mathrm{DM}$ patients). Approximately $13 \%$ of all patients had impaired hypoglycemia awareness $(13.3 \%$ of T1DM and $13.4 \%$ of T2DM patients). A minority had severely impaired hypoglycemia awareness $(1.3 \%$ of T1DM and $3.1 \%$ of T2DM patients).

\section{Fear of Hypoglycemia}

At baseline, responses from T1DM patients indicated a greater fear of hypoglycemia than did those those of T2DM patients (Fig. 1).

\section{Patient Actions due to Hypoglycemia}

A hypoglycemic event resulted in most patients increasing glucose self-monitoring, consulting a doctor or a nurse, and/or reducing the insulin dose (Table 4). 
Table 2 Patient knowledge of hypoglycemia (baseline)

\begin{tabular}{|c|c|c|}
\hline Patient knowledge of hypoglycemia at baseline & $\begin{array}{l}\text { T1DM patients } \\
(N=3135)\end{array}$ & $\begin{array}{l}\text { T2DM patients } \\
(N=6369)\end{array}$ \\
\hline Knowledge of the definition of hypoglycemia $[n / N$ total (\%)] & $3061 / 3121(98.1)$ & $5835 / 6330(92.2)$ \\
\hline Experienced hypoglycemia $[n / N$ total $(\%)]$ & $3069 / 3121(98.3)$ & $5357 / 6329(84.6)$ \\
\hline \multicolumn{3}{|l|}{ Self-recognition of hypoglycemia based on $[n / N$ total (\%)]: } \\
\hline Symptoms only & $874 / 3041(28.7)$ & $1786 / 5245(34.1)$ \\
\hline Low blood glucose only & $117 / 3041(3.8)$ & $325 / 5245(6.7)$ \\
\hline Either symptoms or low blood glucose & $618 / 3041(20.3)$ & $762 / 5245(14.5)$ \\
\hline Both symptoms and low blood glucose & $1432 / 3041(47.1)$ & $2345 / 5245(44.7)$ \\
\hline $\begin{array}{l}\text { Blood glucose measurement to determine if they have hypoglycemia but } \\
\text { provided values inconsistent with standard definitions }(\leq 3.9 \mathrm{mmol} / \mathrm{L} \text {; } \\
70 \mathrm{mg} / \mathrm{dl})[n / N \text { total }(\%)]\end{array}$ & $372 / 2875(12.9)$ & $932 / 4711(19.8)$ \\
\hline $\begin{array}{l}\text { Blood glucose level below which patients considered was a hypoglycemic event } \\
(\mathrm{mmol} / \mathrm{L}) \text { in patients providing values consistent with standard definition, } \\
\text { mean (SD) }\end{array}$ & $3.16(0.550)$ & $3.22(0.534)$ \\
\hline $\begin{array}{l}\text { Blood glucose level below which patients considered was a hypoglycemic event } \\
(\mathrm{mg} / \mathrm{dl}) \text { in patients providing values consistent with standard definition, } \\
\text { mean }(\mathrm{SD})^{\mathrm{a}}\end{array}$ & $56.9(9.91)$ & $58.0(9.62)$ \\
\hline $\begin{array}{l}\text { Blood glucose level below which patients considered was a hypoglycemic event } \\
(\mathrm{mmol} / \mathrm{L}) \text { in patients providing values inconsistent with standard definition, } \\
\text { mean (SD) }\end{array}$ & $4.34(0.608)$ & $4.47(0.625)$ \\
\hline $\begin{array}{l}\text { Blood glucose level below which patients considered was a hypoglycemic event } \\
(\mathrm{mg} / \mathrm{dl}) \text { in patients providing values inconsistent with standard definition, } \\
\text { mean }(\mathrm{SD})^{\mathrm{a}}\end{array}$ & $78.2(10.95)$ & $80.5(11.26)$ \\
\hline
\end{tabular}

\section{Impact of Hypoglycemia on Healthcare Services-Direct Costs}

The occurrence of hypoglycemia in the retrospective and prospective parts of the study led patients with T1DM to make additional telephone contact with a doctor or a nurse (15.5 and $9.2 \%$, respectively) or to attend additional clinical appointments (7.1 and 3.0\%, respectively). During the 6 months prior to baseline, 97 (3.5\%) patients with T1DM had a hypoglycemic event requiring hospitalization, and during the 4 weeks after baseline, hypoglycemia occurred in 31 (1.2\%) patients.
In the retrospective period, 652 (16.6\%) patients with T2DM consulted medical professionals by telephone as a result a hypoglycemic event compared to 409 (14.2\%) in the prospective period. Additional clinical appointments were made by $302(7.7 \%)$ patients with T2DM in the 6 months preceding baseline and by 147 (5.1\%) patients during the 4 weeks after baseline. In the 6 months preceding baseline, 141 (3.4\%) patients with T2DM required hospitalization due to hypoglycemia compared to 66 (2.1\%) during the 4 weeks after baseline. 
Table 3 Incidence of hypoglycemic events in the 4 weeks before and 4 weeks after baseline (by diabetes type)

\begin{tabular}{|c|c|c|c|c|}
\hline $\begin{array}{l}\text { Incidence of } \\
\text { hypoglycemic events }\end{array}$ & $\begin{array}{l}\text { T1DM patients: } 4 \\
\text { weeks before } \\
\text { baseline }(N=3052)\end{array}$ & $\begin{array}{l}\text { T1DM patients: } 4 \\
\text { weeks after baseline } \\
(N=3052)\end{array}$ & $\begin{array}{l}\text { T2DM patients: } 4 \\
\text { weeks before } \\
\text { baseline }(N=6218)\end{array}$ & $\begin{array}{l}\text { T2DM patients } 4 \\
\text { weeks after baseline } \\
(N=6218)\end{array}$ \\
\hline $\begin{array}{l}\text { Number of patients with } \\
\text { any hypoglycemic event } \\
{[n(\%)]}\end{array}$ & $2560(84.3)$ & $2583(85.0)^{a}$ & $3509(57.0)$ & $3312(53.8)^{a}$ \\
\hline $\begin{array}{l}\text { Incidence rate ratio } \\
\text { ( } 4 \text { weeks after } / 4 \text { weeks } \\
\text { before) }\end{array}$ & 1.55 & & 1.19 & \\
\hline $\begin{array}{l}95 \% \mathrm{CI} \text { for incidence } \\
\text { ratio }\end{array}$ & $1.45,1.65$ & & $1.11,1.27$ & \\
\hline $\begin{array}{l}\text { Number of patients with a } \\
\text { severe hypoglycemic } \\
\text { event }[n(\%)]\end{array}$ & $365(12.2)$ & $395(13.0)$ & $408(6.7)$ & $469(7.6)$ \\
\hline $\begin{array}{l}\text { Incidence rate ratio } \\
\text { ( } 4 \text { weeks after } / 4 \text { weeks } \\
\text { before) }\end{array}$ & 1.30 & & 1.35 & \\
\hline $\begin{array}{l}95 \% \mathrm{CI} \text { for incidence } \\
\text { ratio }\end{array}$ & $1.07,1.58$ & & $1.07,1.70$ & \\
\hline $\begin{array}{l}\text { Number of patients with a } \\
\text { nocturnal hypoglycemic } \\
\text { event }\end{array}$ & $1305(43.8)$ & $1142(38.8)$ & $1358(22.7)$ & $1024(17.3)$ \\
\hline \multicolumn{5}{|l|}{$[n(\%)]$} \\
\hline $\begin{array}{l}\text { Incidence rate ratio } \\
\text { ( } 4 \text { weeks after } / 4 \text { weeks } \\
\text { before) }\end{array}$ & 0.77 & & 0.70 & \\
\hline $\begin{array}{l}95 \% \text { CI for incidence } \\
\text { ratio }\end{array}$ & $0.69,0.85$ & & $0.64,0.77$ & \\
\hline $\begin{array}{l}\text { Number of patients with a } \\
\text { non-severe } \\
\text { hypoglycemic event } \\
{[n(\%)]}\end{array}$ & $2490(82.9)$ & $2550(84.5)$ & $3420(57.0)$ & $3238(53.7)$ \\
\hline $\begin{array}{l}\text { Incidence rate ratio } \\
\text { ( } 4 \text { weeks after/4 weeks } \\
\text { before) }\end{array}$ & 1.56 & & 1.16 & \\
\hline $\begin{array}{l}95 \% \mathrm{CI} \text { for incidence } \\
\text { ratio }\end{array}$ & $1.46,1.67$ & & $1.09,1.24$ & \\
\hline
\end{tabular}

CI Confidence interval

${ }^{a}$ Reported previously by Khunti et al. [13] 


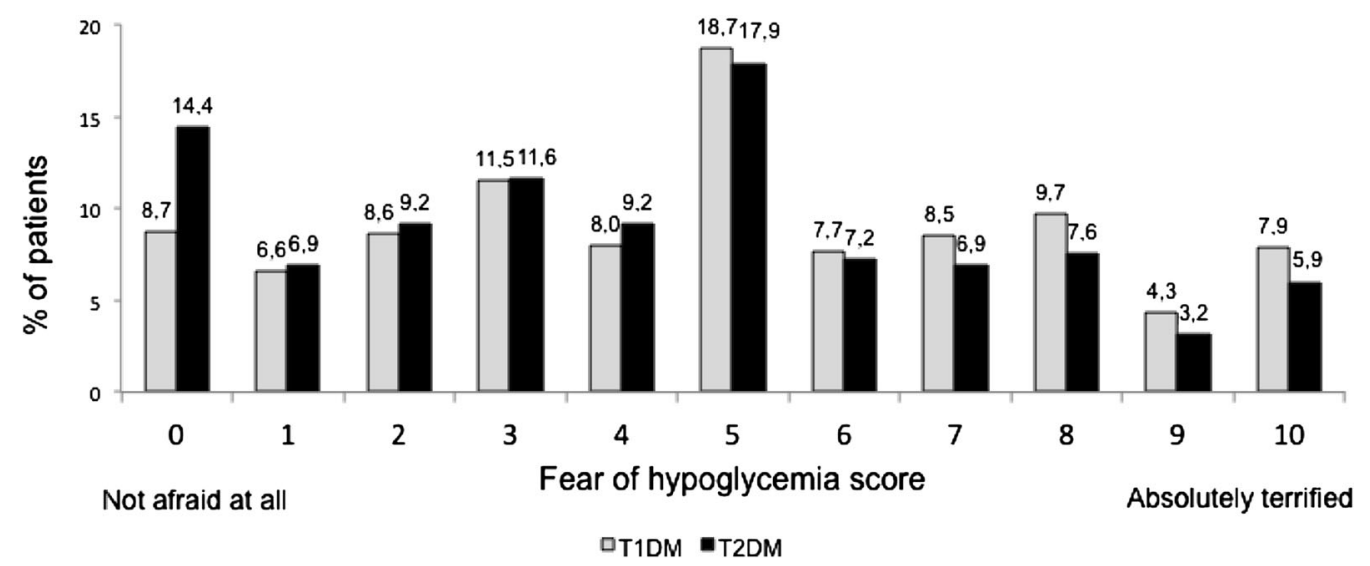

Fig. 1 Fear of hypoglycemia by diabetes type at baseline. TIDM Type 1 diabetes mellitus, T2DM type 2 diabetes mellitus

Table 4 Patient actions resulting from a hypoglycemic event 6 months before and 4 weeks after baseline by diabetes type

\begin{tabular}{|c|c|c|c|c|}
\hline Patient actions & $\begin{array}{l}\text { T1DM patients: } 6 \\
\text { months before } \\
\text { baseline }(N=2797)\end{array}$ & $\begin{array}{l}\text { T2DM patients: } 6 \\
\text { months before } \\
\text { baseline }(N=4129)\end{array}$ & $\begin{array}{l}\text { T1DM patients: } 4 \\
\text { weeks after baseline } \\
(N=2515)\end{array}$ & $\begin{array}{l}\text { T2DM patients: } 4 \\
\text { weeks after baseline } \\
(N=3140)\end{array}$ \\
\hline $\begin{array}{l}\text { Consulted their } \\
\text { doctor/nurse }[n(\%)]\end{array}$ & $1938(70.7)$ & $2960(75.3)$ & $1266(53.0)$ & $1822(63.2)$ \\
\hline $\begin{array}{l}\text { Required any form of } \\
\text { medical assistance } \\
{[n(\%)]}\end{array}$ & $1954(71.3)$ & $3005(76.5)$ & $1280(53.6)$ & $1843(63.9)$ \\
\hline $\begin{array}{l}\text { Increased carbohydrate } \\
\text { intake (sugar or } \\
\text { snacks) }\end{array}$ & $1352(50.5)$ & $2080(53.0)$ & $1255(52.3)$ & $1544(52.0)$ \\
\hline \multicolumn{5}{|l|}{$[n(\%)]$} \\
\hline $\begin{array}{l}\text { Avoided physical } \\
\text { exercise }[n(\%)]\end{array}$ & $585(22.5)$ & $910(24.0)$ & $499(21.2)$ & $694(23.9)$ \\
\hline $\begin{array}{l}\text { Reduced insulin dose } \\
\quad[n(\%)]\end{array}$ & $1702(63.5)$ & $1720(44.5)$ & $1248(51.7)$ & $1205(40.6)$ \\
\hline $\begin{array}{l}\text { Skipped insulin } \\
\text { injections }[n(\%)]\end{array}$ & $354(13.6)$ & $423(11.2)$ & $199(8.5)$ & $202(6.9)$ \\
\hline $\begin{array}{l}\text { Increased blood glucose } \\
\text { self-monitoring } \\
{[n(\%)]}\end{array}$ & $2059(76.7)$ & $2747(71.0)$ & $1831(75.7)$ & $2152(71.9)$ \\
\hline
\end{tabular}

Impact of Hypoglycemia on Work and Study Attendance-Indirect Costs

Most patients with T1DM enrolled in the study were studying or working (2017 before baseline,
1957 in the 4 weeks after baseline). In the prospective period, $40(2.5 \%)$ of these patients had taken some form of leave from work or studies (mean duration $2.3 \pm 2.15$ days), 68 $(4.3 \%)$ had arrived late to their study or working 
place, and $64(4.0 \%)$ had to leave early due to hypoglycemic events. In the retrospective period prior to baseline, $225(11.4 \%)$ had taken leave (mean duration $4.7 \pm 8.09$ days), 316 (16.0\%) had arrived late, and 309 (15.6\%) had left work/studies early.

Among the 1431 patients with T2DM who were studying or employed in the 4-week prospective period, 19 (2.5\%) had taken leave from work or studies (mean duration $2.8 \pm 4.97$ days), 20 (2.7\%) had arrived late to their place of study or work, and 37 (4.9\%) had to leave early due to hypoglycemic events. In the retrospective period prior to baseline, 74 $(5.1 \%)$ had taken leave (mean duration $3.3 \pm 3.09$ days), 91 (6.4\%) had arrived late, and $120(8.4 \%)$ had left work/studies early.

\section{DISCUSSION}

The manner in which patients perceive hypoglycemia, how they handle hypoglycemic events and to what extent these complications affect patient actions and healthcare utilization were part of the HAT survey. Although these data were not presented for the total HAT population in a previous publication reporting the global HAT results [13], we consider such information to be important with respect to providing further insights into hypoglycemia prevention. Therefore, we undertook a detailed examination of these data for the CEE subpopulation.

We observed similar percentages of patients who reported hypoglycemic events in the retrospective and prospective phase of our study. Our interpretation is that once patients started the study, they became more compliant and thus their diabetes was better controlled, possibly including a lower actual rate of hypoglycemia.

Impaired hypoglycemia awareness is one of the strongest risk factors for severe hypoglycemia [17] and has been reported to increase the risk of severe hypoglycemia in T1DM patients by up to sixfold [18]. Data on the proportion of T1DM and T2DM patients unaware of hypoglycemia varies significantly among studies [11, 18-25]. In our study, most T1DM patients $(85.4 \%)$ reported a normal level of hypoglycemia awareness, and only $13.3 \%$ of T1DM patients reported an impaired awareness.

The difference in the percentage of patients reporting impaired hypoglycemia awareness in this study as compared to previous research may be explained by the different ways the patient responses were classified. Most studies conducted to date have used a rigid classification proposed by Pedersen-Bjergaard et al. [26]. In our study, patients who answered the question 'Do you have symptoms when you have a low sugar level?' with 'always' or 'usually' were classified as having a normal level of hypoglycemia awareness, those who answered 'occasionally' were classified as impaired, and those who answered 'never' were classed as severely impaired. However, this classification of hypoglycemia awareness relies on patients' subjective assessments and as such was not validated. Therefore, this methodology needs to be considered as one of the study limitations.

In our study, the fear of hypoglycemia was slightly higher in patients with T1DM than in patients with T2DM. However, most T1DM and T2DM patients scored their fear level as 5 in the 10-point scale (where 10 was 'absolutely terrified'). Hypoglycemia fear influences glycemic variability, dietary patterns, and physical activity in patients with T1DM, as shown by MartynNemeth et al. whose patients increased calorie intake and reduced physical activity due to their fear of hypoglycemia [27]. Other studies have found that fear of hypoglycemia is associated with diabetes-related QoL and psychological well-being $[28,29]$. The fear of hypoglycemia is also a major reason for discontinuation of diabetes medications by T2DM patients $[29,30]$.

The occurrence of a hypoglycemic event resulted in most of the patients in our study increasing glucose self-monitoring and/or consulting a doctor or a nurse. Patients with T1DM were slightly more likely to increase the frequency of glucose self-monitoring compared to T2DM patients, but they were also more aware of hypoglycemic events. However, more than half of the T2DM patients decreased the insulin dose and some skipped insulin injections, which can in turn lead to poor glycemic control and increased risk of related health consequences, such as CV disorders. 
The results of our study reflect patient reactions reported in previous studies. Fulcher et al. followed patient responses to nocturnal and daytime non-severe hypoglycemic events and reported that these patients decreased insulin dosage, contacted a healthcare professional, and performed additional blood testing in the week following the event [31]. Brod et al. also reported similar patient reactions to non-severe nocturnal hypoglycemia, namely, extra blood glucose level tests and reduced insulin dosage [32].

In our study we found that hypoglycemia resulted in an increased use of healthcare services and a decrease in work/study productivity-responses supported by previous research [31-33]. In the analysis by Fidler et al., hypoglycemia was associated with a reduction in QoL, increased fear and anxiety, reduced productivity, and increased healthcare costs [34]. Widz et al. estimated the average monthly direct cost of a hypoglycemic event to be approximately 700 EUR for severe events and 40 EUR for non-severe events [35]. In addition, Goldstein et al. found that severe hypoglycemic events increased the use of healthcare resources and healthcare costs during the month after the event as compared to the month before, with hospital admissions increasing by almost by $100 \%$ for T1DM patients and by $127 \%$ for T2DM patients, and the mean duration of hospitalization being longer [36]. The number of outpatient visits increased by 37\% (T1DM) and $47 \%$ (T2DM). As a result, total monthly healthcare costs increased by $46 \%$ in T1DM patients and by $87 \%$ in T2DM patients [36].

An earlier analysis from seven European countries revealed that approximately $10 \%$ of both daytime and nocturnal non-severe hypoglycemic events led to mean work-time loss of about 1-3 h [33]. Annual costs of severe hypoglycemic events in nine European countries were estimated to be approximately 380,000 EUR in Macedonia ranging up to 58,430,000 EUR in Spain. When expressed as cost per drugtreated patient, the costs ranged from 5.5 EUR in Bulgaria to 17.7 EUR in Spain. The differences were attributable to the costs of a single event treatment and general differences in rates [37].
We also report how hypoglycemia affected patient absenteeism: patients arrived late at work/study, had to leave early, and $2.5 \%$ of them needed to take sick leave. Hypoglycemic events also led to an increase in healthcare services usage. Therefore, minimizing hypoglycemia risk while maintaining good glycemic control may reduce the overall costs of diabetes by diminishing direct costs related to the use of healthcare services and indirect costs by increasing work productivity.

The limitation of the HAT was its observational design with a longer retrospective time horizon and much shorter duration of the prospective phase. Therefore, the comparisons between the results from the retrospective and prospective phases should be interpreted with caution, mainly because of possible recall bias. For example, healthcare utilization or work or study attendance seem to be much lower during the retrospective phase than in the prospective phase, but this difference may be a consequence of underreporting, caused by a recall bias. Another limitation relates to the eligibility criterion that only patients attending routinely scheduled clinical consultations could be enrolled in the study. Illiterate patients or patients otherwise unable to complete a written survey, i.e. patients at the lowest cultural/socioeconomic level were excluded from the study, possibly introducing a population bias. However, the study included a large patient population and allowed us to determine the real-life incidence of hypoglycemia as reported by patients. In addition, the HAT study enabled assessment of the impact of hypoglycemia on patients' reactions, use of healthcare service, and work/study productivity. Another strong feature of the HAT study was that during the prospective period, patient diaries were used in addition to Part 2 of the SAQ to reduce recall bias. While the use of patient-reported data from the diaries in addition to Part 2 of the SAQ may have increased the reliability of the data pertaining to the prevalence of hypoglycemia, it has the potential to overestimate hypoglycemia rates.

It should be also highlighted that this analysis is entirely based on patient self-reported data. Patient-reported outcomes provide a clear 
picture of the patient's perspective and perception. On the other hand, they are inevitably subjective and susceptible to imprecision and variation. Nevertheless, such self-assessments are inherent elements of a patient-centered healthcare system [38], which is particularly suited to diabetes where disease self-management is crucial for proper treatment.

\section{CONCLUSIONS}

In conclusion, our study shows that hypoglycemia impacts patients' personal and social functioning and leads to additional healthcare usage and loss of productivity. Based on these results, we suggest that there is a room for improving education relating to the way hypoglycemia is recognized by patients. We believe that the results of our study can be used to identify cost-effective solutions for improving blood glucose control and the QoL of patients with DM.

\section{ACKNOWLEDGEMENTS}

Funding. The study and article processing charges were funded by Novo Nordisk. All authors had full access to all of the data in this study and take complete responsibility for the integrity of the data and accuracy of the data analysis.

Authorship. All named authors meet the International Committee of Medical Journal Editors (ICMJE) criteria for authorship for this manuscript, take responsibility for the integrity of the work as a whole, and have given final approval to the version to be published.

Medical Writing and/or Editorial Assistance. The authors thank Proper Medical Writing, especially Maria Kołtowska-Haggstrom, PhD, Katarzyna Domek-Lopacinska, PhD and Malgorzata Paradowska, MSc, who provided writing and editorial support and Julia Bates, PhD, who provided linguistic review.
Medical writing, editorial support and linguistic review were funded by Novo Nordisk.

Disclosures. All authors are members of the RISE faculty sponsored by Novo Nordisk. M Andel has received honoraria in last 5 years from Astra Zeneca, Eli Lilly and Novo Nordisk. M Boyanov has received grants and honoraria from Amgen, AstraZeneca, Berlin-Chemie Menarini, Boehringer-Ingelheim, Eli Lilly, Merck, Novartis, Novo Nordisk, Sanofi, Sharp \& Dohme, Servier. L Czupryniak has received grants and honoraria from AstraZeneca, Boehringer-Ingelheim, Eli Lilly, Johnson\&Johnson, Merck, Novo Nordisk, Sanofi, Sharp \& Dohme Servier. L Duvnjak has received grants and honoraria from Merck, Sharp \& Dohme, Boehringer-Ingelheim, Novo Nordisk, Sanofi, Eli Lilly, Novartis, Servier, AstraZeneca, Amgen. $M$ Haluzik has received grants and honoraria from Amgen, AstraZeneca, Boehringer-Ingelheim, Bristol-Myers Squibb, Eli Lilly, Janssen, Johnson\&Johnson, Novartis, Novo Nordisk, Pfizer and Sanofi. A Janez has received grants and honoraria from Amgen, AstraZeneca, Boehringer-Ingelheim, Eli Lilly, Medtronic, Merck, Novo Nordisk, Sanofi, Sharp \& Dohme. $P$ Kempler has received honoraria from AstraZeneca, Bayer, Boehringer-Ingelheim Eli-Lilly MSD, Novartis, Sanofi. A Kretowski has received honoraria from Boehringer-Ingelheim, Novo Nordisk, Sanofi. N Lalic has received honoraria for speaking engagements from Astra Zeneca, Boehringer-Ingelheim, Novo Nordisk, Sanofi. L Madcasy declares no other conflict of interest. $\mathrm{K}$ Strojek has received honoraria for speaking engagements from Boehringer-Ingelheim Eli Lilly, Novo Nordisk, Polfa-Tarchomin, SanofiAventis, Servier, K Strojek has participated in clinical trials for Amgen, Astra Zeneca, Pfizer. $\mathrm{T}$ Tankova has received grants and honoraria from AstraZeneca, Boehringer-Ingelheim, Eli Lilly, Merck, Novartis, Novo Nordisk, Sanofi, Servier, Sharp \& Dohme. I Tarnowska is employed by Novo Nordisk. M Zychma is employed by Novo Nordisk and holds Novo Nordisk shares.

Compliance with Ethics Guidelines. This study was conducted in accordance with the 
Declaration of Helsinki (2004) and the International Conference on Harmonization (ICH) Guidelines for Good Clinical Practice (1996). The study design was approved by the countryspecific regulatory authorities and ethical committees. All participants of the study provided signed informed consent.

Open Access. This article is distributed under the terms of the Creative Commons Attribution-NonCommercial 4.0 International License (http://creativecommons.org/licenses/ by-nc/4.0/), which permits any noncommercial use, distribution, and reproduction in any medium, provided you give appropriate credit to the original author(s) and the source, provide a link to the Creative Commons license, and indicate if changes were made.

\section{REFERENCES}

1. American Diabetes Association. Standards of medical care in diabetes-2017. Diabetes Care. 2017;40[Suppl 1]:S1-135.

2. Action to Control Cardiovascular Risk in Diabetes Study Group, Gerstein HC, Miller ME, et al. Effects of intensive glucose lowering in type 2 diabetes. N Engl J Med. 2008;358(24):2545-59. https://doi. org/10.1056/NEJMoa0802743.

3. Zoungas S, Patel A, Chalmers J, et al. Severe hypoglycaemia and risks of vascular events and death. N Engl J Med. 2010;363(15):1410-8. https://doi. org/10.1056/NEJMoa1003795.

4. Desouza CV, Bolli GB, Fonseca V. Hypoglycaemia, diabetes and cardiovascular events. Diabetes Care. 2010;33(6):1389-94. https://doi.org/10.2337/dc092082 .

5. Zinman B, Wanner C, Lachin JM, Fitchett D, Bluhmki E, Hantel S, Mattheus $M$, Devins $T$, Johansen OE, Woerle HJ, Broedl UC, Inzucchi SE, EMPA-REG OUTCOME Investigators. Empagliflozin, Cardiovascular Outcomes, and Mortality in Type 2 Diabetes. N Engl J Med. 2015;373(22):2117-28. https://doi.org/10.1056/ NEJMoa1504720.

6. Marso SP, Daniels GH, Brown-Frandsen K, et al. Liraglutide and cardiovascular outcomes in type 2 diabetes. N Engl J Med. 2016;375(4):311-22. https://doi.org/10.1056/NEJMoa1603827.
7. Yaffe K, Falvey CM, Hamilton N, et al. Association between hypoglycaemia and dementia in a biracial cohort of older adults with diabetes mellitus. JAMA Intern Med. 2013;173(14):1300-6. https://doi.org/ 10.1001/jamainternmed.2013.6176.

8. Vexiau P, Mavros P, Krishnarajah G, Lyu R, Yin D. Hypoglycaemia in patients with type 2 diabetes treated with a combination of metformin and sulphonylurea therapy in France. Diabetes Obes Metab. 2008;10[Suppl 1]:16-24. https://doi.org/10. 1111/j.1463-1326.2008.00883.x.

9. Frier BM. How hypoglycaemia can affect the life of a person with diabetes. Diabetes Metab Res Rev. 2008;24(2):87-92. https://doi.org/10.1002/dmrr. 796.

10. Seaquist ER, Anderson J, Childs B, et al. Hypoglycemia and diabetes: a report of a workgroup of the American Diabetes Association and the Endocrine Society. Diabetes Care. 2013;36(5):1384-95. https://doi.org/10.2337/dc12-2480.

11. Östenson CG, Geelhoed-Duijvestijn P, Lahtela J, Weitgasser R, Markert Jensen M, Pedersen-Bjergaard U. Self-reported non-severe hypoglycaemic events in Europe. Diabet Med. 2014;31(1):92-101. https:// doi.org/10.1111/dme.12261.

12. Kenny C. When hypoglycemia is not obvious: diagnosing and treating under-recognized and undisclosed hypoglycemia. Prim Care Diabetes. 2014;8(1):3-11. https://doi.org/10.1016/j.pcd.2013. 09.002 .

13. Khunti K, Alsifri S, Aronson R, et al. Rates and predictors of hypoglycaemia in 27585 people from 24 countries with insulin-treated type 1 and type 2 diabetes: the global HAT study. Diabetes Obes Metab. 2016;18(9):907-15. https://doi.org/10.1111/ dom. 12689 .

14. Brath H, Paldánius PM, Bader G, Kolaczynski WM, Nilsson PM. Differences in glycemic control across world regions: a post-hoc analysis in patients with type 2 diabetes mellitus on dual antidiabetes drug therapy. Nutr Diabetes. 2016;6(7):e217M. https:// doi.org/10.1038/nutd.2016.25.

15. American Diabetes Association. Standards of medical care in diabetes-2015. Diabetes Care. 2015;38[Suppl 1]:S1-93.

16. Workgroup on Hypoglycemia, American Diabetes Association. Defining and reporting hypoglycemia in diabetes: a report from the American Diabetes Association Workgroup on Hypoglycemia. Diabetes Care. 2005;28(5):1245-9.

17. Wohland T, Holstein JD, Patzer OM, et al. New risk and protective factors for severe hypoglycaemia in 
people with type 1 diabetes. Nutr Metab Cardiovasc Dis. 2017;27(5):407-14. https://doi.org/10.1016/j. numecd.2016.12.006.

18. Geddes J, Schopman JE, Zammitt NN, Frier BM. Prevalence of impaired awareness of hypoglycaemia in adults with type 1 diabetes. Diabet Med. 2008;25(4):501-4. https://doi.org/10.1111/j.14645491.2008.02413.x.

19. Hendrieckx C, Hagger V, Jenkins A, Skinner TC, Pouwer F, Speight J. Severe hypoglycemia, impaired awareness of hypoglycemia, and self-monitoring in adults with type 1 diabetes: results from Diabetes MILES-Australia. J Diabetes Complications. 2017;31(3):577-82. https://doi.org/10.1016/j. jdiacomp.2016.11.013.

20. Weitgasser R, Lopes S. Self-reported frequency and impact of hypoglycaemic events in insulin-treated diabetic patients in Austria. Wien Klin Wochenschr. 2015;127(1-2):36-44. https://doi.org/10. 1007/s00508-014-0626-1.

21. Peene B, D'Hooge D, Vandebrouck T, Mathieu C. Patient-reported frequency, awareness and patientphysician communication of hypoglycaemia in Belgium. Acta Clin Belg. 2014;69(6):439-45. https://doi.org/10.1179/2295333714Y.0000000050.

22. Kulzer B, Seitz L, Kern W. Real-world patient-reported rates of non-severe hypoglycaemic events in Germany. Exp Clin Endocrinol Diabetes. 2014;122(3):167-72. https://doi.org/10.1055/s0033-1363688.

23. Schopman JE, Geddes J, Frier BM. Prevalence of impaired awareness of hypoglycaemia and frequency of hypoglycaemia in insulin-treated type 2 diabetes. Diabetes Res Clin Pract. 2010;87(1):64-8. https://doi.org/10.1016/j.diabres.2009.10.013.

24. Gehlaut RR, Dogbey GY, Schwartz FL, Marling CR, Shubrook JH. Hypoglycemia in type 2 diabetesmore common than you think: a continuous glucose monitoring study. J Diabetes Sci Technol. 2015;9(5):999-1005. https://doi.org/10.1177/ 1932296815581052.

25. Büyükkaya Besen D, Arda Sürücü H, Koşar C. Selfreported frequency, severity of, and awareness of hypoglycemia in type 2 diabetes patients in Turkey. PeerJ. 2016;4:e2700. https://doi.org/10.7717/peerj. 2700.

26. Pedersen-Bjergaard U, Pramming S, Thorsteinsson B. Recall of severe hypoglycaemia and self-estimated state of awareness in type 1 diabetes. Diabetes Metab Res Rev. 2003;19(3):232-40. https:// doi.org/10.1002/dmrr.377.
27. Martyn-Nemeth P, Quinn L, Penckofer S, Park C, Hofer V, Burke L. Fear of hypoglycemia: influence on glycemic variability and self-management behavior in young adults with type 1 diabetes. J Diabetes Complications. 2017;31(4):735-41. https://doi.org/10.1016/j.jdiacomp.2016.12.015.

28. Strandberg RB, Graue M, Wentzel-Larsen T, Peyrot $\mathrm{M}$, Wahl AK, Rokne B. The relationships among fear of hypoglycaemia, diabetes-related quality of life and psychological well-being in Norwegian adults with Type 1 diabetes. Diabetes Res Clin Pract. 2017;124:11-9. https://doi.org/10.1016/j.diabres. 2016.12.018.

29. Lopez JM, Annunziata K, Bailey RA, Rupnow MF, Morisky DE. Impact of hypoglycemia on patients with type 2 diabetes mellitus and their quality of life, work productivity, and medication adherence. Patient Prefer Adherence. 2014;8:683-92. https:// doi.org/10.2147/PPA.S58813.

30. Bron M, Marynchenko M, Yang H, Yu AP, Wu EQ. Hypoglycemia, treatment discontinuation, and costs in patients with type 2 diabetes mellitus on oral antidiabetic drugs. Postgrad Med. 2012;124(1):124-32. https://doi.org/10.3810/pgm. 2012.01.2525.

31. Fulcher G, Singer J, Castañeda R, et al. The psychosocial and financial impact of non-severe hypoglycemic events on people with diabetes: two international surveys. J Med Econ. 2014;17(10):751-61. https://doi.org/10.3111/ 13696998.2014.946992.

32. Brod M, Wolden M, Groleau D, Bushnell DM. Understanding the economic, daily functioning, and diabetes management burden of non-severe nocturnal hypoglycemic events in Canada: differences between type 1 and type 2 . J Med Econ. 2014;17(1):11-20. https://doi.org/10.3111/ 13696998.2013 .857676$.

33. Geelhoed-Duijvestijn PH, Pedersen-Bjergaard U, Weitgasser R, Lahtela J, Jensen MM, Östenson CG. Effects of patient-reported non-severe hypoglycemia on healthcare resource use, work-time loss, and wellbeing in insulin-treated patients with diabetes in seven European countries. J Med Econ. 2013;16(12):1453-61. https://doi.org/10.3111/ 13696998.2013.852098.

34. Fidler C, Elmelund Christensen T, Gillard S. Hypoglycemia: an overview of fear of hypoglycemia, quality-of-life, and impact on costs. J Med Econ. 2011;14(5):646-55. 13696998.2011.610852.

35. Widz K, Czech M, Hermanowski T. Cost of hypoglycaemia in patients with diabetes in Poland. 
PHS49. Value Health. 2012;15:A277-575. https:// doi.org/10.1016/j.jval.2012.08.1822.

36. Goldstein D, Chodick G, Shalev V, Thorsted BL, Elliott L, Karasik A. Use of healthcare services following severe hypoglycemia in patients with diabetes: analysis of real-world data. Diabetes Ther. 2016;7(2):295-308. https://doi.org/10.1007/ s13300-016-0169-8.
37. Jakubczyk M, Lipka I, Pawęska J, et al. Cost of severe hypoglycaemia in nine European countries. J Med Econ. 2016;19(10):973-82. https://doi.org/10.1080/ 13696998.2016.1188823.

38. Deshpande PR, Rajan S, Sudeepthi BL, Abdul Nazir CP. Patient-reported outcomes: a new era in clinical research. Perspect Clin Res. 2011;2(4):137-44. https://doi.org/10.4103/2229-3485.86879. 